\title{
OBSERVATIONS ON THE HAEMODYNAMICS OF PULMONARY AND LOBAR ATELECTASIS
}

\author{
BY
}

\author{
J. C. GILROY, V. H. WILSON, AND PAUL MARCHAND \\ From the Department of Medicine and the i horacic Surgical Unit, Baragwanath \\ Hospital, Johannesburg
}

(RECEIVED FOR PUBLICATION JANUARY 26, 1951)

It is well recognized that air-absorption collapse of a iobe of a lung or a whole lung does not necessarily cause arterial anoxia. In the course of our investigation of the role of the anastomoses between the bronchial and pulmonary arteries described by Braus (1934), von Hayek (1940), Verloop (1948), Liebow, Hales, and Lindskog (1949), and Marchand, Gilroy, and Wilson (1950) in disease, we have confirmed this finding, and have made observations on the oxygen saturation of blood from the pulmonary arteries and veins during surgical resection of collapsed lobes.

\section{Arterial Oxygen Saturation in Pulmonary Atelectasis}

The eight patients investigated showed clinical and radiological evidence of complete absorption collapse of either a lung or a lobe of a lung. The duration of the history of respiratory disease varied from three weeks to five years. Samples of femoral arterial and venous blood were examined for oxygen unsaturation by the Haldane method as described by Douglas and Priestley (1937). The oxygen capacity of the blood was determined by haemoglobinometry.

Stammers (1933) investigated the normal arterial oxygen saturation in Johannesburg (altitude 5,750 ft.) by the Van Slyke gas analysis method and found it to range from $92.6 \%$ to $97 \%$. Sixteen clinically normal African negro subjects were used to test the accuracy of the Haldane method against Stammers's findings, and the arterial oxygen saturation in them was found to average $94.6 \%$, ranging from $89 \%$ to $97 \%$. Becklake (personal communication, 1950) investigated 10 normal negroes, using the Van Slyke gas analysis method and saturating the blood with oxygen to determine its oxygen capacity. She obtained values ranging from $91.0 \%$ to $93.5 \%$, the average being $92.14 \%$. In our eight patients, the arterial oxygen saturation ranged from $90 \%$ to $92 \%$, and, can therefore be regarded as lying within the limits of normal. In none of our patients was there clinical evidence of cardiac involvement. In three, catheterization of the principal pulmonary arteries and the heart chambers showed pressures to be within normal limits.

Oxygen Saturation in Pulmonary Vessels of Atelectatic Lobes

In three of the eight patients blood samples were obtained from the pulmonary vessels during operation; in these cases pathological examination of the airless lung tissue was possible after surgical resection. 
In Fig. 1 blood oxygen studies on samples obtained at operation during pneumonectomy in Case 1 are presented. During the operation brilliant red blood was obtained from the left pulmonary artery and contrasted strikingly with the darker blood obtained from the main pulmonary artery before and after ligature of the left

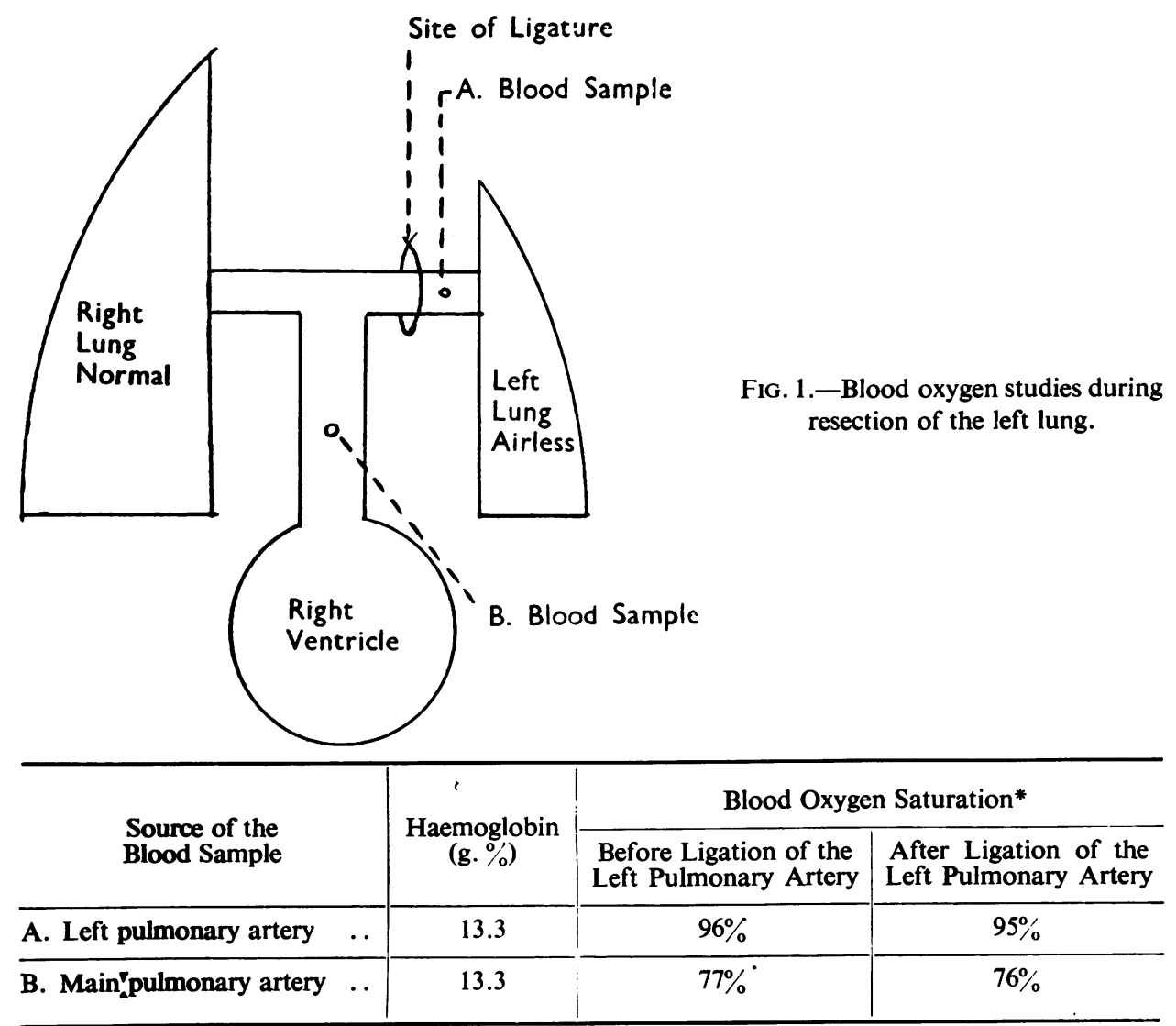

* Samples obtained during $100 \%$ oxygen administration.

pulmonary artery. The samples were taken after all adhesions to the chest wall had been divided and after the anaesthetist had inflated the lungs with pure oxygen. The radiograph of the chest (Fig. 2) showed extensive disease of the left lung with cavitation, stenosis of the left main bronchus, gross displacement of the mediastinum to the affected side, and homogeneous veiling of the left lung. The femoral artery oxygen saturation was $92 \%$ before operation. Pathological examination of the resected lung confirmed these radiological interpretations. By the method described in our previous paper (1950) vinylite injection of the vessels of the resected lung revealed large bronchial arteries and large patent anastomoses throughout the lung tissue. After pneumonectomy the patient made an uneventful recovery.

In Fig. 3 blood oxygen studies on samples obtained during operation for lobectomy in Case 2 are presented. The samples were taken after all adhesions to 


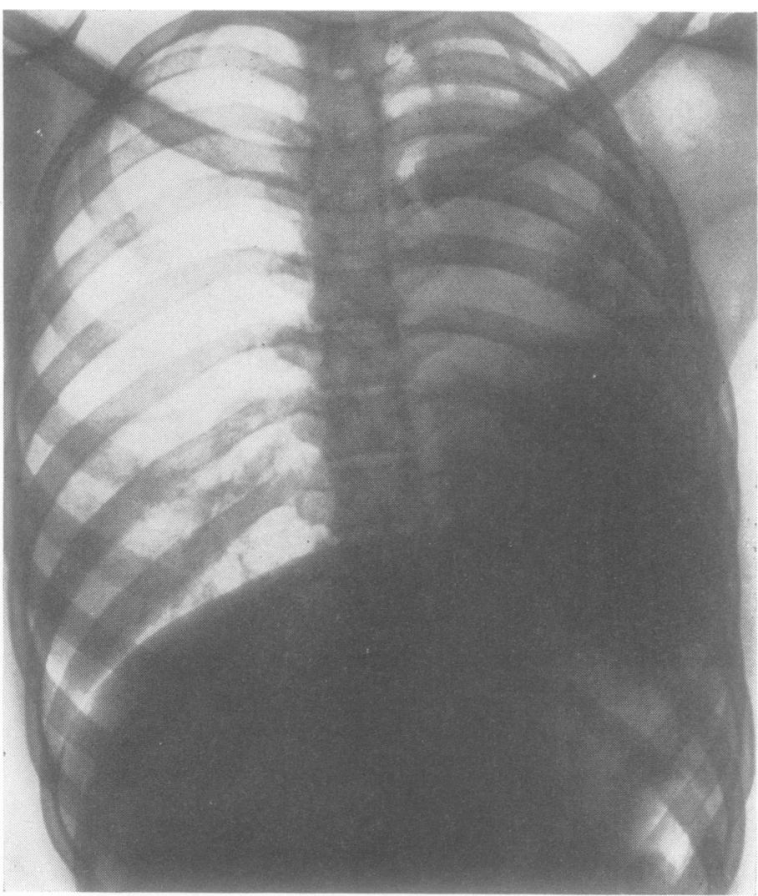

FIG. 2.- Radiograph of the chest of the patient described in Fig. 1.

FiG. 3.-Blood oxygen studies during right lower lote resection for bronchiectasis. The hiatus in the bronchus to the right lower lote represents the site at which the bronchus was divided tefore the blood samples were taken.

Site of Division of the Right Lower Lobe Bronchus

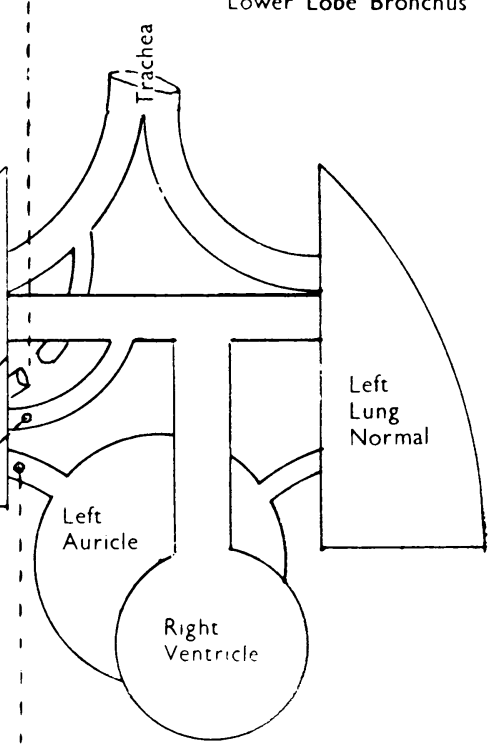

LE. Blood Sample

\begin{tabular}{|c|c|c|}
\hline Source of the Blood ¿ample & $\begin{array}{c}\text { Haemoglobin } \\
(\mathrm{g} . \%)\end{array}$ & Blood Oxygen Saturation* \\
\hline A. Pulmonary artery to the right lower lobe .. & \multirow{2}{*}{17.1} & $100 \%$ \\
\hline B. Pulmonary vein from the right lower lobe & & $86.5 \%$ \\
\hline
\end{tabular}

* Samples obtained after division of the right lower lobe bronchus and during $100 \%$ oxygen administratior. 


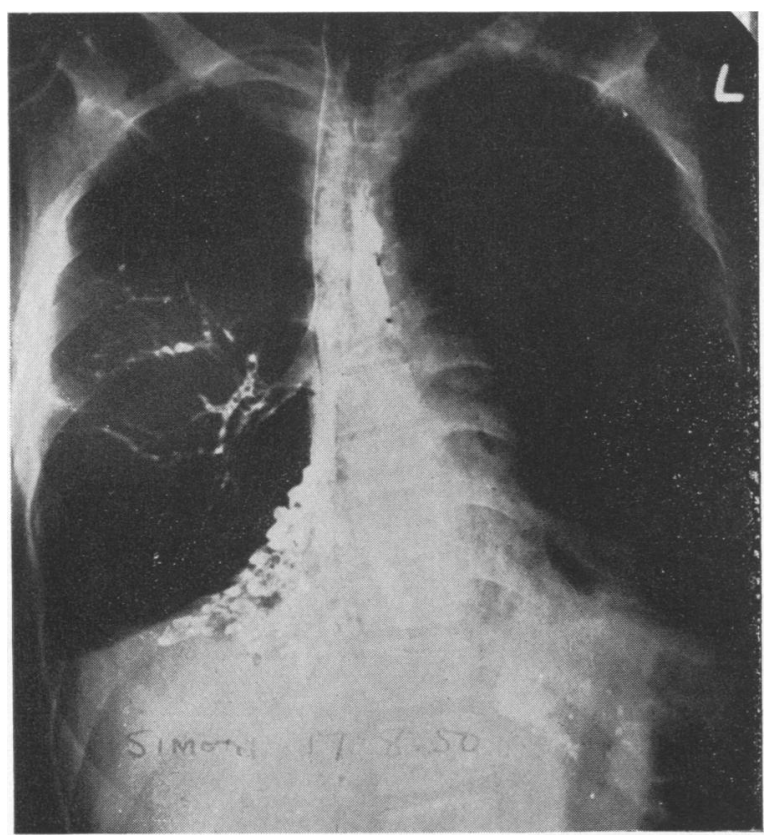

FIG. 4.-Bronchogram of the patient described in Fig. 3.

the chest wall had been separated and after the right lower lobe bronchus had been divided. Brilliant red blood was obtained from the pulmonary artery to the right lower lobe and contrasted strikingly with the darker blood obtained from the corresponding pulmonary vein. The bronchogram of this patient (Fig. 4) showed saccular bronchiectasis involving the whole of the middle and right lower lobes. Before operation, the femoral arterial oxygen saturation was $90 \%$ at rest, and after a standard leg bend exercise $89.5 \%$. The resected right lower lobe with its vessels was examined to confirm that the samples had been taken from the pulmonary artery and vein to this lobe and that no possible confusion between the two had existed. After middle and right lower lobe resection this patient made satisfactory progress.

Case 3 had an airless right lung, stenosis of the right main bronchus, and gross displacement of the heart and mediastinum to the right. Her femoral arterial oxygen saturation was $91.5 \%$ before pneumonectomy was performed. In Fig. 5 blood oxygen studies obtained while the operation was in progress are presented. All samples were taken after all adhesions to the chest wall had been divided and after all hilar structures had been dissected and defined. Brilliant red blood was obtained from the right pulmonary artery before it was ligated. After clamping the right main bronchus, blood which was strikingly darker than the first specimen was obtained from the same site, and this blood showed a significant fall in the oxygen saturation when compared with that of the first sample. When the excised lung was examined after the operation it was found that the clamp around the right main bronchus had included the bronchial artery to the right lung.

The sampling of blood specimens requires considerable care and a knowledge of the distribution of the bronchial artery. In Case 1 no difficulty arose as the bronchus was left undisturbed during the procedure. At the hilum the bronchial artery is closely applied to the posterior aspect of the bronchus and the pulmonary artery and vein lie in front. The dissection was performed and the samples taken from an anterior dissection and therefore well clear of the bronchial artery.

In Case 3 samples were taken before and after clamping of the main bronchus. Due to the close apposition of the bronchial artery to the posterior surface of the bronchus the vessel was included in the clamp and the effect is reflected in the 
FIG. 5.-Blood oxygen studies during right pneumonectomy for bronchial stenosis and bronchiectasis.

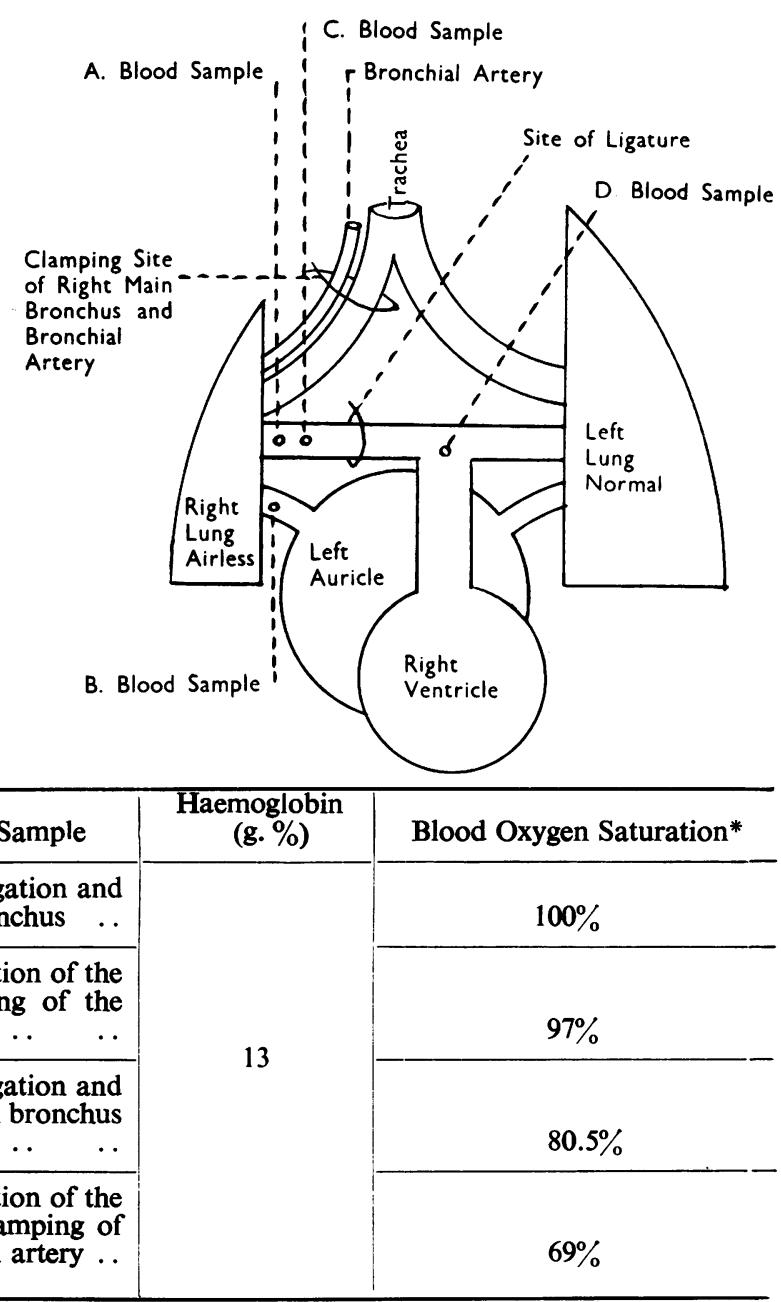

\begin{tabular}{|c|c|c|}
\hline Source and Timing of the Blood Sample & $\begin{array}{l}\text { Haemoglobin } \\
\text { (g. \%) }\end{array}$ & Blood Oxygen Saturation* \\
\hline $\begin{array}{l}\text { A. Right pulmonary artery before ligation and } \\
\text { clamping of the right main bronchus }\end{array}$ & \multirow{4}{*}{13} & $100 \%$ \\
\hline $\begin{array}{l}\text { B. Right pulmonary vein before ligation of the } \\
\text { pulmonary artery and clamping of the } \\
\text { right main bronchus }\end{array}$ & & $97 \%$ \\
\hline $\begin{array}{l}\text { C. Right pulmonary artery before ligation and } \\
\text { after clamping of the right main bronchus } \\
\text { and the bronchial artery .. .. }\end{array}$ & & $80.5 \%$ \\
\hline $\begin{array}{l}\text { D. Main pulmonary artery after ligation of the } \\
\text { right pulmonary artery and clamping of } \\
\text { the bronchus and the bronchial artery .. }\end{array}$ & & $69 \%$ \\
\hline
\end{tabular}

* Samples obtained during $100 \%$ oxygen administration.

results obtained. That some systemic blood was still entering the pulmonary artery after clamping the bronchus is obvious from the difference between the samples from the right pulmonary artery and from the main pulmonary artery. This is readily explained by the fact that though the bronchial artery may be the main source of pulmonary systemic blood it is not the only one. Pleuro-hilar vessels arising from the aorta, usually distal to the origin of the bronchial artery, also anastomose with the pulmonary arteries sub-pleurally (Verloop, 1948 ; Marchand, Gilroy, and Wilson, 1950). The bronchial artery in long-standing cases of absorption collapse is always considerably enlarged, and it is possible to clear it from the bronchus if the hilum is approached posteriorly.

In the resection of the right lower lobe in Case 2 the pulmonary artery and vein were approached from behind. By the time the bronchial artery has reached 
the site of section of the lobar bronchus it has divided into several branches grouped around the periphery of the bronchus. Several branches were incorporated in the clamp, but the profuse anastomoses with the remaining branches and with the pleuro-hilar arteries were sufficient to maintain the bronchial circulation to the lobe even after clamping of its bronchus.

We have tried to confirm these observations made during operations by catheterizing the pulmonary arteries in three of our patients in an attempt to obtain blood from the pulmonary arteries to the collapsed lung or lobe of a lung. We have found it impossible to introduce the catheters into these arteries because they were considerably distorted. The difficulties are greatly increased in cases of lobar collapse because the collapsed lobe is usually overlaid with normal lung, and it is practically impossible to localize the catheter tip accurately on the fluorescent screen. We consider that direct sampling from the pulmonary vessels during operation is the only possible method to achieve certainty of correct blood sampling.

\section{Discussion}

Our investigations have shown that in eight patients in whom considerable portions of respiratory tissue, which still retains its bronchial and vascular connexions, have been rendered functionless, the systemic arterial oxygen saturation has been within normal limits. If pulmonary arterial blood circulated around airless alveoli, considerable lowering of the systemic arterial oxygen would be expected. The striking difference in oxygen saturation between the blood obtained during operation from the main pulmonary artery and that from the left pulmonary artery in Case 1 (Fig. 1) indicates that pulmonary arterial blood was not entering the diseased lung.

The presence of systemic arterial blood in a pulmonary artery under these circumstances can be attributed to the anastomoses between the bronchial and pulmonary arteries which have been described by Braus (1934), von Hayek (1940), Verloop (1948), Liebow and others (1949), and Marchand, Gilroy, and Wilson (1950). Miller (1947) denies their existence and states that vasa vasorum from the bronchial arteries to the pulmonary arteries have been mistaken for anastomoses between the two circulations ; but in a previous paper (1950) we showed that true macroscopic anastomoses existed, and that the lumina of the bronchial arteries communicate with the lumina of the pulmonary arteries by a vessel which has a recognizable anatomical structure.

Bloomer, Harrison, Lindskog, and Liebow (1949) ligated the pulmonary artery in dogs and were able to demonstrate that blood from the bronchial arteries entered the pulmonary arteries by way of anastomoses distal to the site of ligature, and then flowed through the alveolar capillaries and returned to the heart by way of the pulmonary veins. In our cases bronchial arterial blood, after entering the pulmonary arteries across the anastomoses, flowed proximally down the pulmonary artery and mixing with the blood in the main pulmonary artery was transported to the healthy lung. Fig. 6 is a diagram to show the difference between the results of ligation of the pulmonary artery by Bloomer and others (1949) and the conditions which obtained in our patients. In Fig. 6 (B) the distal portion of the pulmonary artery is represented as being thrombosed, as we have previously found in the neighbourhood of suppurative respiratory disease (Marchand and others, 1950). 
The blood oxygen studies in Case 2 not only confirmed the retrograde flow through the pulmonary artery in the airless lobe but also showed that the blood derived from the bronchial arteries was traversing the lung and becoming partly unsaturated before it appeared in the pulmonary vein.

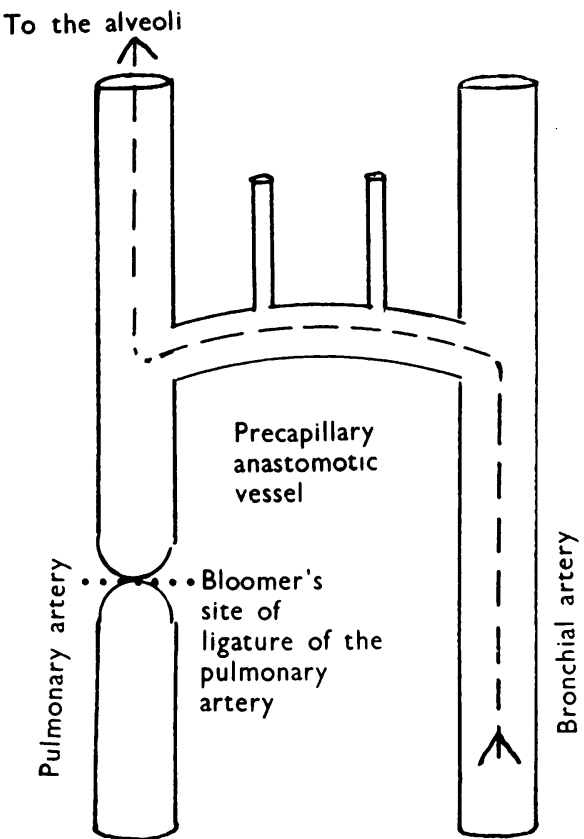

A. Bloomer's experiment. Ligation of the pulmonary artery.

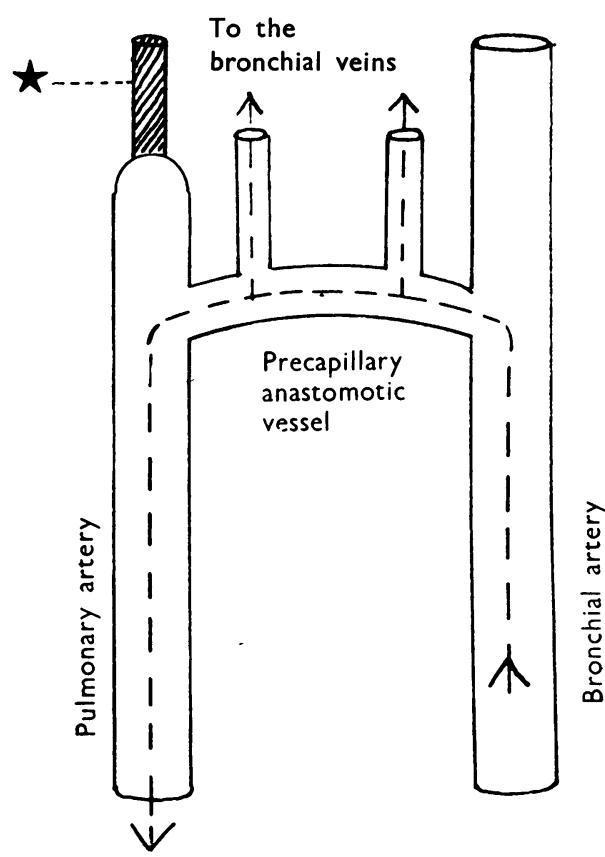

B. In patients with complete depression of respiratory function.

Fig. 6.-Diagram demonstrating the course of the blood flow between the bronchial and the pulmonary circulations in Bloomer's experiment and in patients with complete localized depression of respiratory function. * Thrombosis of the pulmonary radicles found in patients with infected respiratory disease.

The normal pulmonary arterial pressures found during catheterization of the pulmonary arteries in three cases with collapsed lungs in which bronchial to pulmonary blood-flow was presumably occurring are of interest. Liebow and others (1949) have suggested that when bronchial blood flows into the pulmonary arteries in cases of bronchiectasis, the pulmonary arterial pressure might be raised locally ; but it appears that this factor has no effect on the general pulmonary blood pressure.

\section{SUMMARY}

In eight patients with absorption collapse of a lung or a lobe, systemic arterial oxygen saturation was normal.

Studies of the blood oxygen saturation at various sites in the main pulmonary arteries and veins during operations for the removal of a collapsed and functionless lung (two cases) or lobe (one case) suggested that no pulmonary arterial blood was 
traversing the lung and that there was a retrograde flow of blood from the bronchial to the pulmonary arteries.

Our thanks are due to Mr. L. Fatti and Mr. R. G. Crawshaw and Mr. S. Kay, of the Thoracic Surgical Unit, for allowing us to take blood samples during operations. Dr. M. Findlay and the medical staff of the radiological department have been of invaluable assistance to us in our catheterization procedures.

\section{REFERENCES}

Becklake, M. (1950). Personal communication.

Bloomer, W. E., Harrison, W., Lindskog, G. E., and Liebow, A. A. (1949). Amer. J. Physiol., 157, 317 .

Braus, H. (1934). Anatomie des Menschen, 2nd ed., vol. 2, p. $203 . \quad$ Berlin.

Douglas, C. G., and Priestley, J. G. (1937). Human Physiology, 2nd ed., p. 144. Oxford.

Hayek, H. von (1940). Z. Anat. EntwGesch., 110, 412.

Liebow, A. A., Hales, M. R., and Lindskog, G. E. (1949). Amer. J. Path., 25, 211.

Marchand, P., Gilroy, J. C., and Wilson, V. H. (1950). Thorax, 5, 207.

Miller, W.S. (1947). The Lung, 2nd ed., p. 87. Springfield, Ill.

Stammers, A. D. (1933). J. Physiol., 78, 21 P.

Verloop, M. C. (1948). Acta anat., Basel, 5, 171. 